\title{
TECNOLOGIA DA INFORMAÇÃO VERDE NAS ORGANIZAÇÕES: UMA VISÃO ESTRATÉGICA
}

\section{Raul Carlos Costa Queirós}

raulcarlos@gmail.com

Universidade Federal Fluminense UFF, Niterói, Rio de Janeiro, Brasil.

\section{Mirian Picinini Méxas}

mirian_mexas@id.uff.br Universidade Federal Fluminense UFF, Niterói, Rio de Janeiro, Brasil.

\section{Geisa Meirelles Drumond} gmdrumond@id.uff.br

Universidade Federal Fluminense UFF, Niterói, Rio de Janeiro, Brasil.

\section{RESUMO}

Contexto: $O$ crescimento da Tecnologia da Informação (TI) gera impactos ambientais. Benefícios de práticas de TI Verde. Diminuição de impactos ambientais. TI Verde no planejamento estratégico.

Objetivo: Mapear a percepção de especialistas, coordenadores e gestores de TI quanto às práticas de TI verde nas organizações e o seu posicionamento estratégico.

Desenho/Metodologia/Abordagem: Foi realizada uma revisão da literatura que fundamentou uma pesquisa de campo aplicada a 97 gestores e especialistas de TI de organizações, a maioria do estado do Rio de Janeiro e São Paulo, dos mais variados ramos de negócios, no período de dezembro/2018 a janeiro/2019. Os dados foram analisados através de estatística descritiva e de quatro cruzamentos dos resultados sobre práticas de TI Verde, planejamento estratégico e metas ambientais.

Resultados: Observou-se que menos da metade das organizações não tratam a TI Verde como um item estratégico, não a incluindo em seu planejamento estratégico, em sua política ambiental, e não criando metas ambientais.

Implicações práticas: Espera-se que esta pesquisa contribua, demonstrando a importância de reduzir os impactos ambientais, os benefícios das práticas de TI Verde, além de oferecer novas soluções às organizações.

Originalidade/valor: A TI Verde não é tratada de maneira estratégica, o que causa um contraponto: a TI é uma área imprescindível para o negócio e geradora de vantagem competitiva, porém não tem os seus impactos ambientais tratados estrategicamente.

Palavras-chave: TI Verde; Sustentabilidade; Planejamento estratégico; Meio ambiente. 


\section{INTRODUÇÃO}

A evolução da área de Tecnologia da Informação (TI) transformou-se em um ativo estratégico, em um mercado global e competitivo. A relação que era de área suporte passou para um enlace quase que indissolúvel e, em alguns momentos, transformando o modelo de negócio (Oliveira et al., 2012).

O desenvolvimento da TI veio acompanhado de um preço a ser pago, sendo o impacto ambiental. Desse modo, surgiram novos valores sociais e os produtos ecologicamente corretos, os ditos produtos "verdes", que visam a redução dos impactos ambientais nos desenvolvimentos de produtos e serviços (Lunardi et al., 2014).

A sustentabilidade das operações está emergindo como uma grande preocupação para a alta gestão, para os investidores institucionais e os formuladores de políticas em todo o mundo. Os gestores estão interessados em sustentabilidade por causa de suas preocupações sobre o impacto ambiental, as implicações para a futura lucratividade e a reputação da empresa entre as partes interessadas, tais como: clientes ambientalmente conscientes, funcionários, parceiros da cadeia de suprimentos e investidores (Khuntia et al., 2018).

Nessa necessidade de valorização do meio ambiente, sem prejudicar a vantagem competitiva oriunda da $\mathrm{TI}$, surge a TI Verde (Green IT), que se configura como práticas para a aplicação inteligente da TI, utilizando a energia com eficiência e de maneira ecologicamente correta, a fim de diminuir os impactos ambientais em toda a organização (Salles et al., 2013).

A TI Verde busca impactar a TI em todo o seu ciclo de vida, na fabricação dos equipamentos, utilizando menos componentes tóxicos, na sua utilização inteligente e, por fim, no descarte correto (Salles et al., 2013).

A TI Verde também vem causando uma reengenharia dos produtos e serviços de $\mathrm{Tl}$, visando aumentar a eficiência e atender os novos requisitos de conformidade (Pollard, 2016).

Muitas organizações começam a pensar com base no tripé da sustentabilidade: econômico, social e ambiental. Com isto, incluem a TI Verde em suas práticas para atingir metas estratégicas e ambientais (Salles et al., 2013).

Vale ressaltar que a responsabilidade socioambiental deixou de ser uma opção para as organizações, tornando-se uma questão de visão, de estratégia e, muitas vezes, de sobrevivência. Neste contexto, o gerenciamento inteligente da TI pode ser uma alternativa às organizações, não só para minimizar os danos causados ao meio ambiente, mas para melhorar a efetividade do consumo de energia elétrica, diminuir o descarte de equipamentos e reduzir os custos operacionais do negócio, além de desenvolver um ambiente organizacional sustentável em harmonia com os anseios da sociedade atual (Salles et al., 2013).

Em decorrência desse contexto, as empresas vêm emitindo relatórios de sustentabilidade, os quais orientam sobre a TI Verde e apresentam os objetivos, as metas, os indicadores e os resultados destas práticas.

Neste mesmo movimento embarcaram as universidades, cidades e até países, indicando em documentos oficiais práticas para redução do impacto ambiental da $\mathrm{TI}$, o que mostra que a preocupação transcende as organizações comerciais e passa a ser uma preocupação de todos os que utilizam a TI.

Ainda assim, a grande maioria das organizações não pensa, planeja ou executa práticas de TI Verde, ou, quando executa, não o faz em função dos riscos ambientais. Da mesma forma, os motivadores das práticas da TI Verde não são tão conhecidos como se deveria, mesmo que tais práticas resultem em redução de custos (Salles et al., 2013).

Dentro deste contexto, esta pesquisa de abrangência nacional, tem o objetivo de mapear a percepção de especialistas, coordenadores e gestores de TI quanto às práticas de TI verde nas organizações e o seu posicionamento estratégico, e mensurar a sua utilização.

\section{REFERENCIAL TEÓRICO}

Alguns conceitos fundamentais relacionados à sustentabilidade empresarial, à $\mathrm{TI}$, seus impactos ambientais e algumas iniciativas de TI Verde (Green IT) são apresentados nas subseções seguintes.

\section{Sustentabilidade empresarial}

Os conceitos de responsabilidade socioambiental ou sustentabilidade empresarial, na prática, são pautados pela ética e transparência na gestão dos negócios e apontam que uma organização deve ter seus resultados mensurados em três esferas inseparáveis: econômica, social e ambiental. É com base nesse tripé que as empresas devem orientar as suas decisões. Ou seja, a ética nos negócios ocorre quando as decisões de interesse da empresa também respeitam os direitos, os valores e os interesses relacionados aos impactos gerados por ela, seja na sociedade, no meio ambiente ou no futuro da própria organização (Pereira, 2007).

Existem vários índices ao redor do mundo que classificam as empresas de acordo com a sua responsabilidade socioambiental. A maioria analisa as empresas que têm ações na bolsa de valores, verificando dados econômicos, desempenho 
ambiental e social, avaliação de governança corporativa, gestão de risco, mitigação da mudança climática e práticas trabalhistas. É através dessas informações que classificam estas empresas como sustentáveis ou não.

Dessa forma, os acionistas saberão se estão adquirindo ações de empresas sócias ambientalmente corretas e quais as vantagens que elas terão em adquiri-las. A análise envolve quesitos como: política de anticrime e fraudes, gerenciamento da marca, CRM (Customer Relationship Management), engajamento com públicos estratégicos, gerenciamento de fornecedores, riscos e oportunidades nos negócios, política ambiental, inclusão financeira, desenvolvimento do capital humano, indicadores de práticas laborais e direitos humanos, além de retenção e atração de talentos. Nota-se que para se tornar sustentável, as empresas devem demonstrar ética nas relações com funcionários, clientes, fornecedores, parceiros e respeito com o meio ambiente por meio de suas práticas diárias (Nanni; Passos, 2014).

O envolvimento das organizações com questões socioambientais pode se transformar em oportunidades de negócios, contribuindo para melhorar a qualidade de vida dos stakeholders, preservando os recursos naturais e gerando vantagem competitiva. Assim, empresas proativas antecipam a busca pelas melhores alternativas para transformar questões ambientais em questões de negócios. Tais iniciativas convergem para potencializar mudanças organizacionais, que se iniciam pelas estratégias organizacionais, culminando com a parte prática e estruturada em grande parte pela equipe de $\mathrm{TI}$, responsável por concretizar o estado da empresa por meio de processos e tecnologias. Mudanças de visão, de posição e dos produtos visam alterar a direção para a qual a organização está voltada (mudança de estratégia), refletindo em mudanças (Salles et al., 2013).

A integração dos processos de negócio da empresa e a Responsabilidade Social das Empresas (RSE) estão diretamente ligadas ao desempenho da organização e da criação de uma vantagem competitiva (Bohas; Poussing, 2016).

A intensidade da adoção de práticas de TI Verde é a medida que uma organização as incorpora em suas estratégias de prevenção da poluição, gestão de produtos e desenvolvimento sustentável (Ainin et al., 2016).

\section{Tecnologia da informação e seus impactos ambientais}

A rapidez da queda dos custos em TI e o aumento da eficiência e da velocidade dos sistemas e equipamentos representam a mudança nas organizações. O negócio está cada dia mais dependente da área de $\mathrm{TI}$, na qual ela se tornou, além de estratégica, uma vantagem competitiva (Marques; Lazzarini Neto, 2002).
Alguns autores mostram a utilidade da análise da cadeia de valor de Porter para melhor visualizar onde ocorre a conexão entre a TI e o negócio da empresa e, consequentemente, identificar procedimentos para adequação das organizações às possíveis mudanças (Balarine, 2002).

O contínuo crescimento do uso da TI fez surgir uma preocupação relacionada às questões ambientais ligadas ao mau uso e ao descarte dos equipamentos eletrônicos. Somados os gastos necessários para manter a infraestrutura de TI com servidores, computadores, monitores e demais periféricos funcionando adequadamente, a área de TI representa a terceira maior fonte de consumo de energia dentro das grandes empresas (Salles et al., 2013). O outro lado do consumo de energia pode variar conforme os diversos estágios de desenvolvimento econômico, podendo o aumento de consumo ser positivo, mostrando um crescimento econômico (Rahimi; Rad, 2017).

Outro impacto ambiental que resulta nas mudanças climáticas é a crescente emissão de $\mathrm{CO}_{2}$ pelos servidores, que hoje está monitorada e se encontra em frequente evolução (Kern et al., 2015).

A preocupação com o impacto na Tl é tão grande que até os sistemas embarcados dos carros estão sendo analisados com o objetivo de diminuir o consumo de combustível fóssil e a emissão de $\mathrm{CO}_{2}$ na atmosfera (Matamoros de Luis et al., 2015).

As empresas já perceberam que ficar apenas na preocupação não obtém resultado. Por isso, já começam a partir para a ação, principalmente quando o assunto é o esgotamento do desenvolvimento tecnológico tradicional, envolvendo descarte do lixo eletrônico e o desperdício de energia decorrente da deficiência de processamento ou mau uso dos recursos disponíveis (Ferreira; Kirinus , 2010).

\section{TI Verde (Green IT)}

Definem-se iniciativas de TI Verde como investimentos na TI e na sua implantação, uso e gerenciamento, a fim de minimizar o impacto negativo ambiental de TI, das operações de negócios e dos produtos e serviços dos usuários finais (Loeser et al., 2017).

Em alguns casos, as práticas de TI Verde criam nichos específicos de produtos, como o mercado de e-book, sobre o qual as editoras aumentaram a percepção da sua compatibilidade ambiental, reduziram os custos de produção, diminuíram os impactos ambientais e satisfizeram os crescentes clientes ambientalmente pensativos (Hsu et al., 2017).

Alguns termos são utilizados para se referir à TI Verde: Computação Verde, Tecnologia da Informação e Comunica- 
ção (TIC) para o meio ambiente, e TI para o meio ambiente e sustentabilidade (Asadi et al., 2017).

O capital da TI Verde é composto por três dimensões: (1) TI verde capital estrutural, que se refere à infraestrutura de TI verde, incluindo hardware, software, rede e tecnologia da informação, estabelecida sob o conceito de greening; (2) TI verde capital humano, que se refere à capacidade e experiência da equipe de $\mathrm{Tl}$ em possuir conhecimento profissional verde e uma compreensão de conservação de energia em tecnologia, bem como o desenvolvimento pessoal com capacidades de TI verde, através de treinamento e educação; e (3) TI verde capital relacional, referindo-se ao gerenciamento de TI verde e a relação das empresas com parceiros e usuários, adotando um conceito de proteção ambiental na oferta de produtos e serviços (Chuang; Huang, 2015).

Inúmeras ações podem resultar na diminuição do impacto ambiental, por exemplo, a virtualização de servidores, segundo a qual os recursos físicos de um servidor são compartilhados por vários servidores virtuais, minimizando o gasto de energia; a redução ou eliminação de impressões; a mudança de processos de aquisição de novos equipamentos para que atendam requisitos ambientais; e a diminuição da pegada de $\mathrm{CO}_{2}$, como desligamento de computadores em momentos ociosos (Nanni; Passos, 2014).

Juntamente com estas ações, conta-se também com as motivações morais e sociais na utilização de dispositivos de TI para diminuição dos impactos ao meio ambiente, levando-se em conta à iniciativa de cada indivíduo (Koo et al., 2015). Deste modo, as organizações devem elaborar programas de sensibilização sobre questões de TI Verde para seus empregados (Akman; Mishra, 2015). Além da sensibilização, as organizações devem fazer uma avaliação para saber se o seu ambiente está preparado para a adoção das práticas de $\mathrm{TI}$, analisando fornecedores, concorrentes, investidores, parceiros de uma empresa e clientes (Alkali et al., 2017).

As iniciativas de TI Verdes, realmente eficazes, tendem a exigir a colaboração inter organizacional, sendo fundamental para os resultados na quantidade e escala necessárias para o resultado esperado (Oakleaf, 2015).

Existem outras divisões das práticas de TI Verde adotadas pelas organizações, que são classificadas com maior detaIhamento no Quadro 1, relacionando o foco de atuação em sete categorias gerais: práticas de conscientização, datacenter verde, descarte e reciclagem, fontes alternativas de energia, hardware, software e impressão.

Embora algumas dessas práticas exijam elevados investimentos, especialmente aquelas ligadas aos datacenters, às fontes alternativas de energia e à substituição de equipamentos obsoletos por novos, boa parte dessas práticas de sustentabilidade pode ser adotada sem que a saúde financeira da empresa seja comprometida, apenas dependendo do esforço, da vontade dos usuários e do apoio e direcionamento da organização (Dolci et al., 2015).

Com os impactos ambientais da TI, vislumbra-se a Governança de TI Verde, que requer a inclusão de novos atores, controles e métricas, assim como novos indicadores, principalmente no Control Objectives for Information and related Technology (COBIT), que objetiva assegurar que os recursos de TI estejam alinhados com a organização e possam avaliar a responsabilidade socioambiental, atendendo aos padrões internacionais técnicos, profissionais e regulatórios específicos para processos de TI. Já a Information Technology Infrastructure Library (ITIL), biblioteca que reúne as melhores práticas

Quadro 1. Práticas de TI verde

\begin{tabular}{|c|c|}
\hline Prática & Descrição \\
\hline $\begin{array}{l}\text { Virtualização } \\
\text { de servidores }\end{array}$ & $\begin{array}{l}\text { Técnica que permite rodar, simultaneamente, mais de um sistema operacional em um único equipa- } \\
\text { mento físico. Isto diminui a capacidade de processamento ociosa em cada servidor e permite reduzir } \\
\text { o tamanho (número de servidores) e, portanto, o consumo dos data centers. Embora essa inovação } \\
\text { tenha sido desenvolvida originalmente para poupar custos com máquinas e espaço físico, ela se revelou } \\
\text { vantajosa também para a economia de recursos naturais. }\end{array}$ \\
\hline Paperless & Identificação e eliminação do uso utilização desnecessário de papel. \\
\hline $\begin{array}{l}\text { Descarte correto do lixo } \\
\text { eletrônico }\end{array}$ & $\begin{array}{l}\text { Descarte que não impacte o ambiente, encaminhando o processo correto de retirada } \\
\text { dos materiais tóxicos destes equipamentos. }\end{array}$ \\
\hline Reutilização da água & Reutilização de água do resfriamento do datacenter para o uso na empresa. \\
\hline Gestão de equipamentos & $\begin{array}{l}\text { Baseada em função e recursos, a gestão de equipamentos adequa os seus recursos a sua função na em- } \\
\text { presa, aumentando o seu ciclo de vida na empresa e otimizando as compras de novos equipamentos. }\end{array}$ \\
\hline Gestão de energia & $\begin{array}{l}\text { Práticas de economia de energia, como a implantação de descanso de tela, modo standy by } \\
\text { e hibernação do equipamento, com o objetivo de economizar energia }\end{array}$ \\
\hline Energia alternativa & $\begin{array}{l}\text { Utilização de energias alternativas para abastecimento dos datacenters e equipamentos } \\
\text { utilizados nas organizações. }\end{array}$ \\
\hline
\end{tabular}


da indústria e serviços de $\mathrm{TI}$, deve se adequar tendo que provisionar os custos de uma nova infraestrutura verde. Os modelos citados podem ser úteis na estruturação organizacional, nos processos e nas lideranças, com o objetivo de garantir que a TI suporte e auxilie as estratégias das organizações e a inclusão da sustentabilidade em seus objetivos (Richter, 2013).

\section{METODOLOGIA DA PESQUISA}

Este estudo tem como missão compreender os fatores relacionados à adoção de práticas de TI Verde nas organizações e entender o que otimizar, sendo este um trabalho classificado como pesquisa exploratória que, segundo Gil (2010), tem o intuito de aumentar a familiaridade com o problema e torná-lo mais explícito.

Esta pesquisa também é considerada qualitativa e quantitativa, que, de acordo com Gray (2012), abre a possibilidade de dois tipos de análise de dados: numérica e estatística para os dados quantitativos; e textual temática para os dados qualitativos.

Para um melhor entendimento do método adotado nesta pesquisa, a seguir estão relacionadas as principais etapas que a compõem:

- Etapa 1: Uma revisão da literatura foi realizada para identificar as principais práticas de TI verde e seus benefícios.

- Etapa 2: A partir da revisão da literatura, foi elaborado um questionário que foi submetido a 97 profissionais de $\mathrm{TI}$ de empresas dos mais variados modelos de negócio, que estudaram MBA em duas grandes instituições brasileiras.

- Etapa 3: Antes de aplicar o questionário, foi realizado um pré-teste com um representante de cada tipo de respondente, não havendo mudanças no conteúdo, apenas pequenos ajustes.

- Etapa 4: Os dados foram coletados por meio dos questionários e tabulados para se obter o perfil e a percepção dos respondentes.

- Etapa 5: Foram realizadas três análises de resultados: perfil dos respondentes, perfil de planejamento estratégico e perfil de TI Verde.

- Etapa 6: Foram realizados quatro cruzamentos de alguns resultados: entre a utilização do planejamento estratégico e a existência de metas ambientais; entre a existência de políticas ambientais e o conhecimento das práticas de TI verde; entre práticas de TI
Verde e virtualização de servidores; e entre práticas de $\mathrm{TI}$ verde e descarte de lixo eletrônico.

- Etapa 7 Finalmente, na consolidação da pesquisa, foram descritas as conclusões e propostas para trabalhos futuros.

\section{Caracterização dos sujeitos da pesquisa}

A amostra foi composta por 97 respondentes, sendo o questionário enviado para um mailing de 5.000 profissionais, ex-estudantes de MBA de duas grandes instituições brasileiras localizadas no estado do Rio de Janeiro.

Os respondentes foram divididos em dois grupos, com o objetivo de se obter diferentes visões, conforme apresentado no Quadro 2. No primeiro grupo, composto apenas dos gerentes de TI, buscou-se uma visão estratégica, enquanto o segundo grupo, composto de coordenadores e especialistas de organizações dos mais variados ramos de negócio, trouxe uma visão tático/operacional.

Quadro 2. Caracterização dos sujeitos da pesquisa

\begin{tabular}{|c|c|c|}
\hline$\#$ & Grupo & Descrição \\
\hline 1 & Gerentes de TI & $\begin{array}{c}\text { Gestores da área de TI, } \\
\text { responsáveis por todo o } \\
\text { planejamento e sua execução. }\end{array}$ \\
\hline 2 & $\begin{array}{c}\text { Coordenadores e } \\
\text { Especialistas de TI }\end{array}$ & $\begin{array}{c}\text { Líderes e Especialistas da área } \\
\text { de TI, responsáveis pela execução } \\
\text { das atividades. }\end{array}$ \\
\hline
\end{tabular}

Fonte: Os próprios autores.

\section{ANÁLISE E DISCUSSÃO DOS DADOS}

O objetivo da aplicação do questionário foi obter dos profissionais de TI a percepção dos pontos levantados na literatura sobre a TI Verde, conforme exposto na sequência.

\section{Perfil dos respondentes}

Foram entrevistados 97 profissionais, os quais estão divididos entre os seguintes perfis profissionais, conforme a tabela 1.

Tabela 1. Perfil profissional dos respondentes

\begin{tabular}{|c|c|c|}
\hline Perfis & Quantidade & $\%$ \\
\hline Coordenador de TI & 15 & $15,4 \%$ \\
\hline Especialista de TI & 49 & $50,5 \%$ \\
\hline Gestor de TI & 28 & $28,9 \%$ \\
\hline Outros & 5 & $5,2 \%$ \\
\hline
\end{tabular}

Fonte: Os próprios autores. 
Nota-se que na Tabela 1 apenas cinco respondentes não se encaixam nos perfis planejados da pesquisa, o que representa apenas $5,2 \%$ do total. Com este cenário, o nível de confiança nos dados coletados aumenta de maneira significativa, ficando dentro do que foi planejado, com os demais perfis compreendendo $94,8 \%$.

A Tabela 2 indica a distribuição dos entrevistados segundo a localização das empresas onde trabalham..

Tabela 2. Perfil de localização das empresas dos profissionais entrevistados

\begin{tabular}{|c|c|c|}
\hline Localização & Quantidade & $\mathbf{\%}$ \\
\hline Rio de Janeiro & 64 & $66,0 \%$ \\
\hline São Paulo & 17 & $17,5 \%$ \\
\hline Outros estados & 13 & $13,4 \%$ \\
\hline EUA & 3 & $3,1 \%$ \\
\hline
\end{tabular}

Fonte: Os próprios autores.

A maioria dos respondentes trabalha no Rio de Janeiro (66\%), seguido por São Paulo $(17,5 \%)$ e os demais estados $(13,4 \%)$. Completando a distribuição, a pesquisa obteve três respondentes dos EUA, os quais representam 3,1\% do total. Um ponto a mais nesta caracterização é que $49,5 \%$ das empresas nas quais os entrevistados trabalham são de consultorias e serviços de $\mathrm{Tl}$; os demais respondentes $(50,5 \%)$ estão pulverizados em empresas de educação, petróleo e gás, saúde, terceiro setor e outros.

Na Tabela 3 é demonstrado mais um item positivo: $70,1 \%$ dos profissionais têm mais de 10 anos de experiência na área de TI; no outro extremo - profissionais com pouquíssima experiência (menos de 1 ano) - representam uma parcela bem pequena $(2,1 \%)$. Os demais são divididos entre os que têm de 1 a 5 anos, com $15,4 \%$, e os que têm de 5 a 10 anos de experiência $(12,4 \%)$. Em outra perspectiva, o grupamento daqueles que tem experiência superior à cinco anos compreende $82,5 \%$ dos respondentes. Os menos experientes, com tempo de experiencia inferior a cinco anos, compreendem apenas $17,5 \%$ dos respondentes. Conclui-se que a maior parte dos respondentes são profissionais com bastante experiência e suas respostas representam o perfil da TI das organizações.

Tabela 3. Perfil dos respondentes por experiência

\begin{tabular}{|c|c|c|}
\hline Experiência & Quantidade & $\mathbf{\%}$ \\
\hline Menos de 1 ano & 2 & $2,1 \%$ \\
\hline De 1 a 5 anos & 15 & $15,4 \%$ \\
\hline De 5 a 10 anos & 12 & $12,4 \%$ \\
\hline Mais de 10 anos & 68 & $70,1 \%$ \\
\hline
\end{tabular}

Fonte: Os próprios autores.

\section{Perfil de planejamento estratégico}

Com o grande grau de incerteza dos mercados, as empresas cada vez mais buscam se planejar, traçar objetivos e metas para um determinado período de tempo, assim como utilizar processos de governança, de TI e corporativa. $\mathrm{Na}$ pesquisa, buscou-se verificar se as organizações possuem um planejamento estratégico.

A Tabela 4 retrata exatamente a preocupação com a estratégia da empresa, sendo que $81,5 \%$ dos respondentes afirmaram que as empresas nas quais atuam possuem planejamento estratégico, enquanto $11,3 \%$ afirmaram que as empresas não possuem um planejamento estratégico, e 7,2\% desconhecem se existe ou não esse planejamento. Deve-se ressaltar que não foi objeto desta pesquisa medir o grau de maturidade desse planejamento, mas apenas a existência desse processo na empresa, sendo um item muito importante nesse momento de incertezas nos mercados globais.

Tabela 4. Utilização do planejamento estratégico

\begin{tabular}{|c|c|c|}
\hline $\begin{array}{c}\text { Sua empresa possui } \\
\text { Planejamento Estratégico? }\end{array}$ & Quantidade & \% \\
\hline Desconheço & 7 & $7,2 \%$ \\
\hline Não & 11 & $11,3 \%$ \\
\hline Sim & 79 & $81,5 \%$ \\
\hline
\end{tabular}

Fonte: Os próprios autores.

Outro item da pesquisa é a verificação da preocupação com o meio ambiente pelas empresas. As preocupações são: se a sustentabilidade está incluída em seu planejamento estratégico, se existem metas ambientais, se existe uma política ambiental e se é exigida política ambiental de parceiros e fornecedores. Com estes pontos, foram mostradas as reais preocupações com o meio ambiente.

O primeiro ponto a se verificar foi se existem itens sobre sustentabilidade no planejamento estratégico. A Tabela 5 mostra que mais da metade das empresas possuem itens de sustentabilidade em seu planejamento estratégico $(52,6 \%)$. Porém, 35\% das empresas não possuem estes itens e 12,4\% dos respondentes desconhecem se existe ou não algum planejamento.

Tabela 5. Itens de sustentabilidade no planejamento estratégico

\begin{tabular}{|c|c|c|}
\hline $\begin{array}{c}\text { O planejamento estratégico } \\
\text { possui itens relacionados com } \\
\text { sustentabilidade? }\end{array}$ & Quantidade & $\%$ \\
\hline Desconheço & 12 & $12,4 \%$ \\
\hline Não & 34 & $35 \%$ \\
\hline Sim & 51 & $52,6 \%$ \\
\hline
\end{tabular}

Fonte: Os próprios autores. 
Para que se possa medir e controlar a evolução dos objetivos ambientais é necessário definir metas a serem atingidas. Por isso, verificar se existem metas ambientais é bastante relevante. Os números encontrados na pesquisa mostram que $40,2 \%$ das empresas possuem metas ambientais e $43,3 \%$ não possuem, além de $16,5 \%$ desconhecerem se possuem. Ou seja, os números de quem possui ou não metas são bem parecidos, conforme apresenta a Tabela 6.

Tabela 6. Utilização de metas ambientais

\begin{tabular}{|c|c|c|}
\hline $\begin{array}{c}\text { A empresa possui metas } \\
\text { ambientais? }\end{array}$ & Quantidade & $\mathbf{\%}$ \\
\hline Desconheço & 16 & $16,5 \%$ \\
\hline Não & 42 & $43,3 \%$ \\
\hline Sim & 39 & $40,2 \%$ \\
\hline
\end{tabular}

Questionados sobre a exigência organizacional de os parceiros de negócio e fornecedores possuírem uma política ambiental, 20,6\% disseram que as empresas exigem, $49,5 \%$ disseram que não exigem e $29,9 \%$ não souberam responder (Tabela 7).

Tabela 7. Política ambiental para parceiros e fornecedores

\begin{tabular}{|c|c|c|}
\hline $\begin{array}{c}\text { A empresa exige política } \\
\text { ambiental dos seus parceiros e } \\
\text { fornecedores? }\end{array}$ & Quantidade & \% \\
\hline Desconheço & 29 & $29,9 \%$ \\
\hline Não & 48 & $49,5 \%$ \\
\hline Sim & 20 & $20,6 \%$ \\
\hline \multicolumn{2}{|c}{ Fonte: Os próprios autores. }
\end{tabular}

\section{Análises cruzadas}

Visando o aprofundamento das análises e a averiguação das relações entre elementos, alguns dados foram cruzados, com posterior análise baseada na estratégia das organizações e na TI Verde, que se interagem e se influenciam.

Tabela 9. Práticas de TI verde

\begin{tabular}{|c|c|c|c|c|c|}
\hline Práticas de TI Verde & $\begin{array}{c}\text { Nunca } \\
\text { utiliza }\end{array}$ & Pouco utiliza & Sempre utiliza & $\begin{array}{c}\text { Utiliza com } \\
\text { frequência }\end{array}$ & Utiliza em alguns casos \\
\hline Virtualização & $12,4 \%$ & $11,3 \%$ & $22,7 \%$ & $33,0 \%$ & $20,6 \%$ \\
\hline Paperless & $14,4 \%$ & $32,0 \%$ & $20,6 \%$ & $22,7 \% \%$ & $6,1 \%$ \\
\hline Descarte lixo eletrônico & $28,9 \%$ & $9,3 \%$ & $20,6 \%$ & $22,7 \%$ & $18,5 \%$ \\
\hline Reutilização da água & $63,9 \%$ & $9,3 \%$ & $10,3 \%$ & $10,3 \%$ & $6,2 \%$ \\
\hline Gestão de Equipamentos & $13,4 \%$ & $20,6 \%$ & $14,4 \%$ & $22,7 \%$ & $28,9 \%$ \\
\hline Gestão de Energia & $1,0 \%$ & $18,6 \%$ & $40,2 \%$ & $26,8 \%$ & $13,4 \%$ \\
\hline Energia alternativa & $64,9 \%$ & $15,4 \%$ & $3,1 \%$ & $7,2 \%$ & $9,3 \%$ \\
\hline
\end{tabular}


O cruzamento de dados exposto na Tabela 10 foi o ponto de partida, com o qual se verificou se as empresas que possuem um planejamento estratégico, que são a grande maioria $(n=79)$, também possuem metas ambientais, refletindo a existência de preocupação ambiental. Quando se desafia, essas duas questões trazem algumas informações: das empresas que possuem planejamento estratégico, $45,6 \%$ também possuem metas ambientais, $36,7 \%$ não possuem e $17,7 \%$ dos respondentes não souberam informar sobre essas metas. No que tange às empresas que não possuem o planejamento estratégico, $27,3 \%$ possuem e $72,7 \%$ não possuem metas ambientais.

Tabela 10. Planejamento estratégico $x$ metas ambientais

\begin{tabular}{|c|c|c|c|}
\hline \multirow{2}{*}{$\begin{array}{c}\text { Sua empresa possui pla- } \\
\text { nejamento estratégico? }\end{array}$} & \multicolumn{3}{|c|}{ Possui metas ambientais? } \\
\cline { 2 - 4 } & Desconheço & Não & Sim \\
\hline Desconheço & $28,6 \%$ & $71,4 \%$ & $0,0 \%$ \\
\hline Não & $0,0 \%$ & $72,7 \%$ & $27,3 \%$ \\
\hline Sim & $17,7 \%$ & $36,7 \%$ & $45,6 \%$ \\
\hline
\end{tabular}

Fonte: Os próprios autores.

Os números da Tabela 6 demonstram que existe uma preocupação com metas ambientais, mas em menor proporção do que o esperado, já que as empresas que as possuem somam menos da metade das empresas pesquisadas. Ou seja, as metas ambientais não estão diretamente ligadas ao planejamento estratégico.

Quando o estudo cruza as respostas relativas a existência de política ambiental e o conhecimento sobre as práticas de TI Verde, os dados são bem interessantes, como mostra na Tabela 11.

Das empresas que possuem uma política ambiental, $53,6 \%$ não conhecem as práticas ambientais, ou seja, na sua política ambiental não estão incluídas práticas de TI Verde;
41,5\% possuem uma política ambiental e conhecem práticas de TI Verde, enquanto 4,9\% possuem política ambiental, mas desconhecem as práticas de TI Verde. Nas empresas que não possuem a política ambiental, os números seguem esta tendência: $52,6 \%$ deste universo não conhecem as práticas e $47,4 \%$ conhecem as práticas, conforme. A maior parte das organizações não conhece as práticas de TI Verde, independentemente do fato de possuir ou não política ambiental.

Tabela 11. Política ambiental x conhecimento de práticas de TI verde

\begin{tabular}{|c|c|c|c|}
\hline \multirow{2}{*}{$\begin{array}{c}\text { A empresa possui políti- } \\
\text { ca ambiental? }\end{array}$} & \multicolumn{3}{|c|}{$\begin{array}{c}\text { Você conhece as práticas de TI } \\
\text { Verde? }\end{array}$} \\
\cline { 2 - 4 } & Desconheço & Não & Sim \\
\hline Desconheço & $11,1 \%$ & $50,0 \%$ & $38,9 \%$ \\
\hline Não & $0,0 \%$ & $52,6 \%$ & $47,4 \%$ \\
\hline Sim & $4,9 \%$ & $53,6 \%$ & $41,5 \%$ \\
\hline
\end{tabular}

Fonte: Os próprios autores.

Outro cruzamento realizado foi entre as respostas relacionadas ao conhecimento das práticas de TI Verde e a utilização da técnica de virtualização de servidores. Seguindo o esperado, mais de $95 \%$ das empresas que conhecem as práticas, utilizam, em algum grau, a virtualização. Quando o foco são as empresas que não conhecem as práticas de $\mathrm{TI}$ Verde, também se observa uma proporção elevada de utilização da técnica $(82,4 \%)$, sendo que $41,2 \%$ sempre a utilizam ou a utilizam com frequência (Tabela 12).

Uma das práticas de TI Verde de maior visibilidade é o descarte correto de lixo eletrônico, a partir do qual que se faz doação, reutilização de peças e envio para países com tecnologia para separação dos componentes químicos que compõem os equipamentos. Assim, efetuou-se cruzamento entre as respostas relacionadas ao conhecimento das em-

Tabela 12. Práticas de TI verde $x$ virtualização de servidores

\begin{tabular}{|c|c|c|c|c|c|}
\hline \multirow{2}{*}{$\begin{array}{c}\text { Conhece práti- } \\
\text { cas de TI Verde }\end{array}$} & Nunca utiliza & Pouco utiliza & Sempre utiliza & Utiliza com frequência & \multirow{2}{*}{ Utiliza em alguns casos } \\
\cline { 2 - 6 } & $17,6 \%$ & $15,7 \%$ & $11,8 \%$ & $29,4 \%$ & $25,5 \%$ \\
\hline Não & $4,8 \%$ & $7,1 \%$ & $38,1 \%$ & $33,3 \%$ & $16,7 \%$ \\
\hline Sim & $25,0 \%$ & $0,0 \%$ & $0,0 \%$ & $75,0 \%$ & $0,0 \%$ \\
\hline Desconheço & \multicolumn{5}{|c|}{ Fonte: Os próprios autores. }
\end{tabular}

Tabela 13. Práticas de TI verde $X$ descarte de lixo eletrônico

\begin{tabular}{|c|c|c|c|c|c|}
\hline \multirow{2}{*}{$\begin{array}{c}\text { Conhece práti- } \\
\text { cas de TI Verde }\end{array}$} & \multicolumn{5}{|c|}{ Utiliza o descarte correto do lixo eletrônico? } \\
\cline { 2 - 6 } & Nunca utiliza & Pouco utiliza & Sempre utiliza & Utiliza com frequência & Utiliza em alguns casos \\
\hline Não & $27,5 \%$ & $9,8 \%$ & $25,5 \%$ & $17,6 \%$ & $19,6 \%$ \\
\hline Sim & $28,6 \%$ & $4,8 \%$ & $16,7 \%$ & $30,9 \%$ & $19,0 \%$ \\
\hline Desconheço & $50,0 \%$ & $50,0 \%$ & $0,0 \%$ & $0,0 \%$ & $0,0 \%$ \\
\hline
\end{tabular}


presas sobre as práticas de TI Verde e ao descarte de lixo eletrônico, como indica a Tabela 13.

Verificou-se que $71,4 \%$ das empresas que conhecem as práticas fazem o descarte de lixo eletrônico em algum momento, sendo que $16,7 \%$ sempre o fazem. Curiosamente, esses percentuais foram inferiores aos encontrados entre as empresas que não conhecem as práticas de TI Verde: $72,5 \%$ e $25,5 \%$, nesta ordem. Com esses dados, infere-se que há ampla adoção dessa prática, ao que pode ser justificada pelo fato de essa ser uma das mais divulgadas na mídia.

\section{CONCLUSÃO}

O presente estudo, através da revisão da literatura, identificou as práticas de TI verde e seus benefícios. Em seguida, com base na literatura, foi aplicado um questionário a um grupo de 97 especialistas, coordenadores e gestores de $\mathrm{TI}$, visando identificar se as práticas de TI Verde estariam incluídas no planejamento estratégico das organizações.

Os resultados indicaram que a maior parte dos profissionais possui mais de 10 anos de experiência e trabalham em empresas de consultoria de TI localizadas nos estados do Rio de Janeiro e São Paulo. Quanto às empresas, a maioria possui planejamento estratégico e itens relacionados à sustentabilidade. Contudo, mais da metade delas $(52,6 \%)$ não conhecem as práticas de TI Verde e as que conhecem correspondem a $34,3 \%$. As práticas mais utilizadas pelo conjunto das empresas são a gestão de energia e a virtualização de servidores (>50\%).

A partir da análise cruzada dos dados levantados pelo instrumento de pesquisa, foi possível verificar se as metas ambientais estão incluídas no planejamento estratégico das organizações, e se ter conhecimento sobre as práticas de $\mathrm{TI}$ Verde se relaciona ao seu uso e à existência de uma política ambiental. Constatou-se proporção significante de organizações que não tratam a TI Verde como um item estratégico, não incluindo-a em seu planejamento estratégico e em sua política ambiental, e não criando metas ambientais.

Esta conclusão de que a TI Verde não é abordada de maneira estratégica causa um contraponto: embora a TI, segundo a literatura, seja compreendida como um ativo estratégico, imprescindível para o negócio e geradora de vantagem competitiva, seus impactos ambientais não são tratados estrategicamente. Outro ponto contraditório é o movimento global de criação de produtos e serviços mais "verdes", em que todo seu ciclo de vida é analisado e tratado pelas organizações tratando de forma estratégica. Porém, os impactos da TI não são incluídos, como se não fizessem parte do ciclo de vida.
Fica claro que os impactos da TI estão sendo tratados em outro nível que não o estratégico, não sendo tratados com importância e como prioridade entre os itens do planejamento estratégico.

Espera-se que este estudo possa contribuir para o desenvolvimento no âmbito da redução dos impactos ambientais e sugira mitigações neste intuito.

Com as repostas apresentadas por este estudo, o caminho natural é o aprofundamento em futuras pesquisas, com temas como: maturidade nos processos de TI Verde (criando uma escala para isso), relacionamento da TI Verde com os principais frameworks de governança de TI (COBIT) e qualidade em serviços de TI (ITIL), propondo inclusão de processo de TI Verde. Outro tema que não pode ser esquecido são os impactos da TI Verde na Internet das Coisas (IoT) e na Indústria 4.0.

\section{REFERÊNCIAS}

Ainin, S., Naqshbandi, M.M., Dezdar, S. 2016. Impact of adoption of Green IT practices on organizational performance. Quality and Quantity 50, 1929-1948. https://doi.org/10.1007/ s11135-015-0244-7

Akman, I., Mishra, A. 2015. Sector diversity in Green Information Technology practices: Technology Acceptance Model perspective. Computers in Human Behavior 49, 477-486. https://doi.org/10.1016/j.chb.2015.03.009

Alkali, A.U., Abdul-Azeez, I.A., Mansor, N.N.A., Chikaji, A.I., Dodo, Y.A. 2017. Towards low carbon universities in Nigeria: Agenda for green information technology. Chemical Engineering Transactions 56, 733-738. https://doi.org/10.3303/ CET1756123

Asadi, S., Hussin, A.R.C., Dahlan, H.M. 2017, Organizational research in the field of Green IT: A systematic literature review from 2007 to 2016, Telematics and Informatics 34, 11911249. https://doi.org/10.1016/j.tele.2017.05.009

Balarine, O.F.O. 2002. Tecnologia da informação como vantagem competitiva. Revista de Administração de Empresas 1, 1-11. https://www.scielo.br/pdf/raeel/v1n1/v1n1a05

Bohas, A., Poussing, N. 2016. An empirical exploration of the role of strategic and responsive corporate social responsibility in the adoption of different Green IT strategies. Journal of Cleaner Production 122, 240-251. https://doi.org/10.1016/j. jclepro.2016.02.029

Chuang, S.P., Huang, S.J. 2015. Effects of Business Greening and Green IT Capital on Business Competitiveness, Journal of Business Ethics 128, 221-231. https://doi.org/10.1007/ s10551-014-2094-y 
Dolci, D.B., Lunardi, G.L., Salles, A.C., Alves, A.P.F. 2015. Implementation of Green IT in organizations: a structurational view. Revista de Administração de Empresas 55, 486-497. https:// doi.org/10.1590/S0034-759020150502

Ferreira. A.P., Kirinus, J.B. 2010. A implantação de uma política de TI Verde em uma empresa de sistemas elétricos. XV Simpósio de Ensino, Pesquisa e Extensão, 5-7 out. 2011, disponível em: http://docplayer.com.br/11689311-A-implantacao-de-uma-politica-de-ti-verde-em-uma-empresa-de-sistemas-eletricos-1.html

Gil, A. C. 2010. Como elaborar projeto de pesquisa, 5. ed., Atlas, São Paulo.

Gray, D. E. 2012. Pesquisa no mundo real, Penso, Porto Alegre.

Hsu, C.-L., Chen, M.-C., Lin, Y.-H. 2017. Information technology adoption for sustainable development: green e-books as an example. Information Technology for Development 23, 261280. https://doi.org/10.1080/02681102.2017.1298078

Kern, E., Dick, M., Naumann, S., Hiller, T. 2015. Impacts of software and its engineering on the carbon footprint of ICT. Environmental Impact Assessment Review 52, 53-61. https://doi. org/10.1016/j.eiar.2014.07.003

Khuntia, J., Saldanha, T.J.V., Mithas, S., Sambamurthy, V. 2018. Information Technology and Sustainability: Evidence from an Emerging Economy, Production and Operations Management 27, 756-773. https://doi.org/10.1111/poms.12822

Koo, C., Chung, N., Nam, K. 2015. Assessing the impact of intrinsic and extrinsic motivators on smart green IT device use: Reference group perspectives. International Journal of Information Management 35, 64-79. https://doi.org/10.1016/j. ijinfomgt.2014.10.001

Loeser, F., Recker, J., Brocke, J. vom, Molla, A., Zarnekow, R. 2017. How IT executives create organizational benefits by translating environmental strategies into Green IS initiatives. Information Systems Journal 27, 503-553. https://doi. org/10.1111/isj.12136

Lunardi, G., Simões, R., Frio, R. 2014. TI verde: uma análise dos principais benefícios e práticas utilizadas pelas organizações. Revista Eletrônica de Administração 20, 1-30. https:// doi.org/10.1590/S1413-23112014000100001
Marques, M., Lazzarini Neto, S. 2002. Capital humano e TI gerando vantagem competitiva, Revista de Administração de Empresas 1, 1-16. https://doi.org/10.1590/S167656482002000200016

Matamoros de Luis, M., Argüelles Cruz, A.J., Uriarte Arcia, A.V., Yáñez Márquez, C. 2015. Green Information Technology influence on car owners' behavior: Considerations for their operative support in collaborative eLearning and social networks. Computers in Human Behavior 51, 792-802. https:// doi.org/10.1016/j.chb.2014.11.085

Nanni, H.C., Passos, A.G. 2014. TI Verde - Práticas Sustentáveis para o Descarte de Equipamentos Eletrônicos. Revista Científica Integrada Unaerp 13, No. 3, 1-9.

Oakleaf, M. 2015. Writing information literacy assessment plans: A guide to best practice. Communications in Information Literacy 3, 80-90. https://doi.org/10.1002/asi

Oliveira, L.R., Medeiros, R.M., Terra, P.B., Quelhas, O.L.G. 2012. Sustentabilidade: da evolução dos conceitos à implementação como estratégia nas organizações. Produção 22, 70-82. http://dx.doi.org/10.1590/S0103-65132011005000062

Pereira, A.A. 2007. O tripé da sustentabilidade. Lócus: Ambiente de Inovação Brasileira 13, 38-41.

Pollard, C. 2016. IT - Energy Conservation at Work: People Don't Always Act the Way They Feel, IT Professional, IEEE Publishing 18, 50-56. http://dx.doi.org/10.1109/MITP.2016.9

Rahimi, M., Rad, A.A. 2017. Internet Usage, Electricity Consumption and Economic Growth : Evidence from a Panel of Developing-8 Countries. International Journal of Energy Economics and Policy 7, 152-156. https://ideas.repec.org/a/eco/ journ2/2017-03-19.html

Richter, R. M. 2013. TI Verde: Sustentabilidade por meio da Computação em Nuvem, Centro Estadual de Ensino Tecnológico Paula Souza, São Paulo.

Salles, A., Alves, A., Dolci, D. and Lunardi, G. 2013. Adoção de práticas de TI verde nas organizações: Um estudo baseado em mini casos. IV Encontro de Administração da Informação, 1921 maio de 2013, disponível em: http://repositorio.furg.br/ bitstream/handle/1/5373/2013_EnADI145.pdf?sequence=1

Recebido: 05 mar. 2020

Aprovado: 30 jun. 2020

DOI: $10.20985 / 1980-5160.2020 . v 15 n 2.1629$

Como citar: Drumond, G.M., Queirós, R.C.C., Méxas, M.P. (2020), Tecnologia da Informação Verde nas organizações: uma visão estratégica. Revista $S \& G$ 15, 2, 103-112. https://revistasg.emnuvens.com.br/sg/article/ view/1629 